\title{
A importância dos ODS - Objetivos de Desenvolvimento Sustentável, no desafio da educação para os direitos humanos
}

- La importancia de los ODS - Objetivos de Desarrollo Sostenible, en el desafío de la educación para los derechos humanos

- The importance of the SDGs - Sustainable Development Goals, in the challenge of education for human rights

Resumo: Os Direitos Humanos não são aprendidos estudando-os, mas praticando-os diariamente em todos os contextos, em que o ser humano se desenvolve. São essenciais para desfrutar de uma vida digna, baseada na liberdade, igualdade e dignidade, e refletida nos tratados internacionais, bem como nas constituições de cada Estado. Numa perspetiva histórica, os Direitos Humanos foram-se construindo como uma forma de resistência à opressão e busca pelo bem-estar do indivíduo, grupos ou de comunidades inteiras. Ao longo da história, eles passaram por transformações, para conceituar, especificar e ampliar aqueles incluídos na Declaração Direitos Humanos Universais, de 1948. Os indivíduos tornam-se agentes de mudança no mundo, atuando contra as injustiças, através da concretização dos ODS - Objetivos de Desenvolvimento Sustentável. Eles precisam de conhecimentos, habilidades, valores e

1 Licenciatura em Sociologia. Doutoramento em Teoria Juridico-Politica e Relações Internacionais. Pós Doutoramento em Cooperação Internacional. CICP - Investigadora no Centro de Investigação em Ciência Política da Universidade de Évora. tsliborio@gmail.com 
atitudes que lhes permitam contribuir para o desenvolvimento sustentável. A educação é crucial para a consecução deste desenvolvimento. Pretende-se demonstrar aqui a importância dos ODS, especificamente respeitante a: alterações climáticas e educação para os direitos humanos. Apresentamos os projetos desenvolvidos na Síria, em São Tomé e Príncipe, no Brasil e em Portugal, e as suas tendências para o futuro, tendo em conta as metas a atingir em cada ODS, e como este aspeto pode influenciar o desenvolvimento humano e tornar o mundo mais harmonioso, mais justo e igualitário.

Palavras-chave: Direitos Humanos. ODS. Educação.

Resumen: Los derechos humanos no se aprenden al estudiarlos, sino al practicarlos diariamente en todos los contextos donde se desarrollan los seres humanos. Son esenciales para disfrutar de una vida digna, basada en la libertad, la igualdad y la dignidad, reflejada en los tratados internacionales, así como en las constituciones de cada estado. Desde una perspectiva histórica, los derechos humanos se han construido como una forma de resistencia a la opresión y la búsqueda del bienestar del individuo. A lo largo de la historia, han sufrido transformaciones, para conceptualizar y especificar los incluidos en la Declaración Universal de Derechos Humanos de 1948. Los individuos se convierten en agentes de cambio en el mundo, actuando contra las injusticias, a través del logro de los ODS - Objetivos de Desarrollo Sostenible. Necesitan conocimientos, habilidades, valores y actitudes que les permitan contribuir al desarrollo sostenible. Por lo tanto, la educación es crucial para el logro de este desarrollo. Su objetivo es demostrar la importancia de los ODS, específicamente en relación con el cambio climático y la educación para los Derechos Humanos. Presentamos los proyectos desarrollados en Siria, Santo Tomé y Príncipe, Brasil y Portugal, y sus tendencias para el futuro, teniendo en cuenta los objetivos a alcanzar en cada ODS, y cómo este aspecto puede influir en el desarrollo humano y hacer que mundo más armonioso, más justo y más igualitario.

Palabras clave: Derechos humanos. ODS. Educación.

Abstract: Human rights are not learned by studying them, but by practicing them daily in all contexts where human beings develop. They are essential to enjoy a dignified life, based on freedom, equality and dignity, reflected in international treaties, as well as in the constitutions of each state. From a historical perspective, human rights have been built as a form of resistance to 
oppression and the search for the well-being of the individual. Throughout history, they have undergone transformations, to conceptualize and specify those included in the 1948 Universal Human Rights Declaration. Individuals become agents of change in the world, acting against injustices, through the achievement of the SDGs - Sustainable Development Goals. Education is therefore crucial to the achievement of this development. It is intended to demonstrate the importance of the SDGs, specifically regarding climate change; education for human rights. We present the projects developed in Syria, São Tomé and Príncipe, Brazil and Portugal, and their trends for the future, taking into account the goals to be achieved in each SDG, and how this aspect can influence human development and make the more harmonious, fairer and more egalitarian world.

Keywords: Human rights. ODS, Education.

\section{Educação, direitos humanos e injustiça}

A ideia moderna de Direitos Humanos nasce da "crescente consciencialização contra a opressão ou a inadequada atuação por parte da autoridade estadual [...] sendo hoje uma categoria jurídica" (MARTINS, 2006, p. 83). A Educação, considerada primariamente como uma missão de família e de religião, nem sempre foi considerada um direito. No entanto, com a emergência do moderno Estado-Nação, a educação converteu-se num assunto de interesse público e da responsabilidade do Estado (MONTEIRO, 2013). É no século XX que a educação ganha uma dimensão jurídica. Após a 2a Guerra Mundial, através de vários planos normativos, tornou-se num direito do ser humano.

Cada vez mais, a Humanidade parece sentir que a linguagem dos Direitos Humanos é aquela que afirma, de um modo mais coerente, a"igualdade moral de todos os indivíduos", reconhecendo, embora, que é uma linguagem que se produz num mundo de conflito, de argumentação, de deliberação. (IGNATIEFF, 2011, p. 111). Tendo presente os desafios da globalização, os Direitos Humanos parecem estar a contribuir para a emergência de uma outra conceção de democracia, na linha da democracia comunicativa. (RAWLLS, 1998). Os Direitos Humanos são parte de um direito razoável dos povos, que transcende os Estados e que, por isso, podem fixar limites às instituições domésticas; são uma condição necessária da legitimidade do regime político e da decência da sua ordem jurídica, para além de fixarem um limite ao pluralismo entre os povos. (BAUMAN, 2003)

As Nações Unidas proclamaram o período entre 1 de janeiro de 1995 a 31 de dezembro de 2004 como: A Década das Nações Unidas para a Educação 
em Direitos Humanos. Os profissionais da educação, atuando em escolas, universidades, e outras instituições de ensino, são convidados a desenvolver um papel relevante, tanto no desenvolvimento de programas de treino e desenvolvimento de materiais de trabalho, quanto para incorporar, nos currículos próprios, em todos os níveis, os propósitos e os objetivos de uma educação em direitos humanos. (ONU, 2017).

A educação constitui-se em um dos lugares naturais de aplicação, consolidação e expansão dos Direitos Humanos: como um direito-chave cuja negação é especialmente perigosa para o princípio democrático da igualdade civil e política; como uma arena de luta por direitos e com direitos; enfim, como um outro nome da justiça social. Por conseguinte, a educação não pode ficar indiferente aos valores e à "formação de uma cultura de respeito à dignidade humana mediante a promoção e a vivência dos valores da liberdade, da justiça, da igualdade, da solidariedade, da cooperação, da tolerância e da paz". (BENEVIDES, 2016, p. 309).

Assim, a educação para os Direitos Humanos é uma prática participativa com o objetivo de mobilizar as pessoas e as comunidades e capacitá-las com os conhecimentos, atitudes, valores e aptidões para usufruir e exercer esses direitos e para respeitar e defender os direitos dos outros. "A educação em direitos humanos parte de três pontos essenciais: primeiro, é uma educação de natureza permanente, continuada e global; segundo, é uma educação necessariamente voltada para a mudança; e terceiro, é uma inculcação de valores, para atingir mentes e não apenas instrução, meramente transmissora de conhecimentos. Ou esta educação é compartilhada por aqueles que estão envolvidos no processo educacional - os educadores e os educandos - ou ela não será educação e muito menos educação em Direitos Humanos". (BENEVIDES, 2016, p.315).

$\mathrm{O}$ direito à educação é, portanto, um direito humano fundamental que exige dos Estados a "obrigação de respeitar, proteger e implementar" (MOREIRA; GOMES, 2013, p.195). Exige, portanto, que o Estado aja positivamente em relação aos indivíduos na concretização deste direito. A expressão "educação para todos" só ultimamente começou a ser fomentada enquanto um direito, sendo-lhe reconhecido o seu valor estratégico universalmente. Em 2001, Kofi Annan, no Relatório do Milénio, da ONU, diz-nos "A Educação - desde o ensino primário até à educação permanente - é o motor da nova economia global. Está no centro do desenvolvimento, do progresso social e da liberdade humana"2. Tal afirmação permite-nos salientar a importância da educação e da qualificação da população enquanto alavanca de desenvolvimento de um país. (UNRIC, 2013).

A dignidade do ser humano não repousa apenas na racionalidade; no processo educativo procuramos atingir a razão, mas também a emoção, pois

2 Relatório do Milénio. Disponível em: https://unric.org/pt/kofi-annan-gana/. Acesso em: 23 jul. 2019. 
o homem não é apenas um ser que pensa e raciocina, mas que é capaz de amar e de odiar, que é capaz de sentir indignação e enternecimento, que é capaz da criação estética. Unamuno dizia que o que mais nos diferencia dos outros animais é o sentimento, e não a racionalidade. ${ }^{3} \mathrm{O}$ ser humano possui a sua dignidade explicitada através de características que são únicas e exclusivas da pessoa humana; além da liberdade como fonte da vida ética. Como dizia Kant (apud BENEVIDES, 2000, p. 17), o ser humano é o único ser cuja existência é um valor absoluto, um fim em si e não um meio para outras coisas.

A Educação em Direitos Humanos é um dos mais importantes de combate às violações de direitos humanos, já que educa na tolerância, na valorização da dignidade e nos princípios democráticos. A educação é o caminho para qualquer mudança social, que se deseje realizar dentro de um processo democrático. (MAGENDZO, 2006). É igualmente por meio dessa educação que se pode começar a mudar as perceções sociais radicais, discriminatórias e violentas, na maioria das vezes, legitimadoras das violações de direitos humanos e reconstruir as crenças e valores sociais fundamentados no respeito ao ser humano e em conformidade com os preceitos democráticos e as regras do Estado de Direito. (TAVARES, 2006).

Desde a proclamação da DNUEDS - Década das Nações Unidas da Educação para o Desenvolvimento Sustentável, esta teve por objetivos reorientar políticas de educação, práticas e investimentos canalizados para a sustentabilidade, sendo responsabilidade da UNESCO assegurar a criação de mecanismos apropriados para otimizar a implementação da Década. (UNESCO, 2017).

Mary Robinson (Ex-Alta Comissária das Nações Unidas para os Direitos Humanos) refere que a "educação em matéria de direitos humanos e em prol dos direitos humanos constitui, em si mesma, um direito, isto é, o direito de todos a conhecer os direitos e a dignidade de todos e as formas de garantir o seu respeito" ${ }^{\prime \prime}$. Não só a educação é um direito fundamental, mas também a educação em direitos humanos. (Conferência Mundial de Direitos Humanos, 2013).

\section{A Agenda 2030 em nome da dignidade humana}

Esta Agenda é um plano de ação para as pessoas, para o planeta e para a prosperidade. Ela também busca fortalecer a paz universal com mais liberdade. Reconhecemos que a erradicação da pobreza em todas as suas formas e dimensões, incluindo a pobreza extrema, é o maior desafio global e

\footnotetext{
3 Educação em Direitos Humanos: do que se trata? Disponível em: https://respeitarepreciso.org.br/educacao-em-direitos-humanos-de-que-se-trata/. Acesso em: 25 jul. 2019.

4 Cf. https://unric.org/pt/o-que-sao-os-direitos-humanos/. Acesso em: 18 fev. 2021.
} 
um requisito indispensável para o desenvolvimento sustentável. Os 17 Objetivos de Desenvolvimento Sustentável e as 169 metas demonstram a escala e a ambição desta nova Agenda Universal, construindo-se sobre o legado dos Objetivos de Desenvolvimento do Milénio e concluirão o que estes não conseguiram alcançar. Eles buscam concretizar os direitos humanos de todos e alcançar a igualdade de gênero e o empoderamento das mulheres e meninas, e são integrados e indivisíveis, equilibrando as três dimensões do desenvolvimento sustentável: económica, social e a ambiental.

Nunca os líderes mundiais se comprometeram a uma ação comum e um esforço via uma agenda política tão ampla e universal. Criam juntos um caminho rumo ao desenvolvimento sustentável, dedicando-se coletivamente à busca do desenvolvimento global e da cooperação vantajosa para todos, que podem trazer enormes ganhos para todos os países e todas as partes do mundo. "Seremos a primeira geração a ter sucesso em acabar com a pobreza; assim como também a última a ter uma hipótese de salvar o planeta". (NAÇÕES UNIDAS, 2015).

A importância do Desenvolvimento Sustentável é reconhecida nas três cúpulas influentes de desenvolvimento sustentável: a Conferência das Nações Unidas sobre Meio Ambiente e Desenvolvimento de 1992 (UN Conference on Environment and Development - UNCED), no Rio de Janeiro; a Cúpula Mundial sobre Desenvolvimento Sustentável de 2002 (World Summit on Sustainable Development - WSSD), em Johanesburgo, África do Sul; e a Conferência das Nações Unidas sobre Desenvolvimento Sustentável de 2012 (UN Conference on Sustainable Development - UNCSD), também no Rio de Janeiro, Brasil.

Para que todos possam atuar em favor dos ODS, temos de trabalhar intensamente, com vista ao desenvolvimento sustentável, de competências de sustentabilidade específicas para cada ODS. Por isso, "é vital não apenas incluir conteúdos relacionados aos ODS nos currículos, mas também utilizar a pedagogia transformadora orientada para a ação" (UNESCO, 2017, p.11-54). Nas palavras de Ban Ki-Moon, "os 17 ODS são a nossa visão comum para a Humanidade e um contrato social entre os líderes mundiais e os povos". De facto, importa ressalvar que esta é uma Agenda com uma dimensão universal, a implementar por todos os países, e não apenas nos países em desenvolvimento, como o caso dos Objetivos de Desenvolvimento do Milénio (ODM), no período entre 2000 e 2015 (ONU, 2017, p. 5).

Portugal defendeu a necessidade de esta Agenda assentar numa verdadeira partilha de responsabilidades, entre atores públicos e privados e entre países desenvolvidos e em desenvolvimento, além da tradicional abordagem Norte-Sul. No que concerne ao debate sobre a adaptação do sistema das Nações Unidas aos desafios inerentes à Agenda 2030, 
a escala do compromisso político assumido, sublinhando a necessidade de garantir a eficiência e eficácia de um sistema que se deverá basear numa articulada cooperação e complementaridade entre os diferentes atores, nos planos global, regional e nacional, explorando as sinergias e interdependências entre as respetivas competências e estratégias, evitando duplicações e procurando maximizar capacidades e impacto (ONU, 2017, p. 11).

No que diga respeito a Portugal, materializa nos ODS 4, 5, 9, 10, 13 e 14 as suas prioridades estratégicas na implementação da Agenda 2030 para o Desenvolvimento Sustentável. Tal como definido no Programa Nacional de Reformas,

\begin{abstract}
Portugal atribui uma importância central à educação, formação e qualificação, ao longo da vida, procurando inverter atrasos e exclusões históricos, com impactos diretos no bem-estar das pessoas, no desempenho económico, no combate à pobreza, na promoção da igualdade e coesão social, da cidadania e do ambiente. Por isso, reconhece-se como desígnio prioritário e via transversal para alcançar vários outros Objetivos de Desenvolvimento Sustentável, o ODS4 Educação de Qualidade (CONSELHO EMPRESARIAL PARA O DESENVOLVIMENTO SUSTENTÁVEL, 2017).
\end{abstract}

A tarefa fundamental do Estado é promover a igualdade entre mulheres e homens, sendo princípio fundamental da Constituição da República Portuguesa e estruturante do Estado de direito democrático a não discriminação em função do sexo ou da orientação sexual.

\begin{abstract}
A prossecução de políticas ativas de igualdade entre mulheres e homens é um dever inequívoco de qualquer governo, assente numa obrigação que se estende à sociedade em geral. A dimensão da igualdade de género deve, por isso, ser tida em consideração na conceção e execução de qualquer política pública. A igualdade entre mulheres e homens é um imperativo e um objetivo social em si mesmo, essencial a uma vivência plena da cidadania, constituindo um pré-requisito para se alcançar uma sociedade mais moderna, justa e equitativa, e um desenvolvimento verdadeiramente sustentável, no respeito pleno da dignidade humana. Concluiu-se, assim, na priorização nacional dos ODS, a particular relevância do ODS5 Igualdade de Género (ONU, 2017, p.10).
\end{abstract}

Por outro lado, [...] o crescimento económico, o desenvolvimento social e a adaptação e mitigação das alterações climáticas estão interligados com o investimento em infraestruturas adequadas, numa indústria moderna, empreendedora e sustentável, no progresso tecnológico e na digitalização da economia (p.12).

Portugal encontra-se empenhado em responder a estes desafios, apresentando estratégias, programas que procuram apoiar e desenvolver os setores das infraestruturas, da indústria e da inovação e mobilizam para o efeito um conjunto de recursos, públicos e privados. Reveste-se, pois, de cariz prioritário, a prossecução do ODS 9 - Indústria, Inovação e Infraestruturas. 
Neste contexto de prosperidade, o novo paradigma de desenvolvimento do território, procura combater as desigualdades socioeconómicas e as disparidades regionais, com base em estratégias de promoção de justiça social. As prioridades definidas pelo Governo em 2016 continuam a orientar a intervenção para o futuro e passam por:

[...] combater a pobreza e a exclusão social, ativando medidas com foco particular nos grupos mais vulneráveis; reduzir as desigualdades prosseguindo a elevação do rendimento disponível das famílias e promover o acesso de todos os cidadãos a bens e serviços públicos de primeira necessidade, reforçando esta vertente no combate ao empobrecimento e na defesa da dignidade humana (ONU, 2017, p. 11-12).

A intervenção estrutural preconizada nestas áreas deverá, assim, pautar-se por

[...] critérios sustentáveis e multifacetados, abrangendo áreas tão diversas como a saúde, a educação, um mercado de trabalho mais justo e inclusivo a recuperação e uma repartição de rendimentos mais equilibrada, através de medidas de política salarial, de proteção social e de natureza fiscal ajustadas às mutações da realidade social e que garantam os mínimos sociais aos cidadãos mais vulneráveis. (ONU, 2017, p. 12).

Este contexto coloca um cariz prioritário no prosseguimento do ODS10 - Reduzir as Desigualdades.

O desafio para o futuro passa por garantir que

"[...] Governo, setor privado e sociedade civil assegurem a implementação dos compromissos acordados - no âmbito da redução das emissões de gases com efeito de estufa, aumento da quota-parte das energias renováveis, melhoria da eficiência energética e reforço da capacidade das interligações energéticas - aumentando assim gradualmente o nível de ambição no âmbito do Acordo de Paris". (ONU, 2017, p. 13).

As respostas às alterações climáticas devem ser enquadradas e integradas de forma a promover o correto planeamento e desenvolvimento de uma economia resiliente, competitiva e de baixo carbono. Realce-se, neste sentido, a preponderância do ODS 13 - Ação Climática. (ONU, 2017, p. 13).

Portugal assume um papel de relevo, de dimensão internacional na sustentabilidade e governança dos Oceanos. Considerando a importância que o Mar assume do ponto de vista da sua História, geografia e identidade,"Portugal tem apoiado os esforços das Nações Unidas, na promoção de uma mobilização global para a proteção dos Oceanos e para a exploração sustentável dos seus recursos" (p.13). Este enquadramento sustenta a priorização de um último - em ordem, que não em importância - ODS, o ODS 14 - Proteger a Vida Marinha.

Deste modo, quanto aos ODS referenciam-se os seguintes: 
ODS 1: erradicar a pobreza, em todas as suas dimensões e lugares. Globalmente, o número de pessoas a viver em extrema pobreza diminuiu mais da metade; em 1990 eram 1,9 bilhão. Contudo, 836 milhões de pessoas ainda vivem na extrema pobreza: cerca de uma, em cada cinco pessoas em regiões em desenvolvimento, vive com menos de 1,25 dólar por dia. O Sul da Ásia e a África Subsaariana são o lar da esmagadora maioria das pessoas vivendo em extrema pobreza. Altos índices de pobreza são frequentemente encontrados em países pequenos, frágeis e afetados por conflitos. Destacam-se os Programas Estratégicos de Cooperação nas áreas do emprego, proteção social, formação profissional, inclusão social, luta contra a pobreza, com Timor-Leste, Cabo Verde, Angola, Moçambique e Guiné-Bissau. (ONU, 2017, p.13-15).

ODS 2: erradicar a fome, alcançar a segurança alimentar, melhorar a nutrição e promover a agricultura sustentável. A vasta maioria das pessoas do mundo passando fome, vive em países em desenvolvimento, onde $12,9 \%$ da população é subnutrida. Ásia é o continente com a população que passa mais fome. A África Subsaariana é a região com a mais alta prevalência de fome, cerca de uma, em cada quatro pessoas, está subnutrida. Ao nível da cooperação internacional, tem vindo a ser reforçada a cooperação transfronteiriça, ao nível não só da Península Ibérica, mas também ao nível do Mediterrâneo, onde Portugal integra a Parceria para a Investigação e Inovação na Região do Mediterrâneo, para a gestão sustentável da água e dos sistemas de produção alimentar. (ONU, 2017, p.16).

ODS 3: garantir o acesso à saúde de qualidade e promover o bem-estar para todos, em todas as idades. A cada dia, morrem 17 mil crianças a menos do que em 1990, porém mais de seis milhões de crianças ainda morrem a cada ano, antes do seu quinto aniversário. Desde 2000, vacinas de sarampo preveniram aproximadamente 15,6 milhões de mortes. (ONU, 2017, p.18).

ODS 4: garantir o acesso à educação inclusiva, de qualidade e equitativa, e promover oportunidades de aprendizagem ao longo da vida para todos. A matrícula na educação primária, em países em desenvolvimento, chegou a 91\%, mas 57 milhões de crianças permanecem fora da escola; mais da metade das crianças que não se matricularam na escola vivem na África Subsaariana. Estima-se que $50 \%$ das crianças fora da escola, com idade escolar primária, vivem em áreas afetadas por conflitos. $O$ mundo conquistou a igualdade na educação primária entre meninas e meninos, mas poucos países alcançaram essa meta em todos os níveis de educação. Relativamente à cooperação com países parceiros, Portugal tem sido o motor no desenvolvimento de ações na CPLP, destacando-se o alargamento de escolas portuguesas em Macau, Timor-Leste, Angola e Moçambique e a abertura de uma escola em Cabo Verde e em São Tomé e Príncipe. (ONU, 2017, p.19). 
ODS 5: alcançar a igualdade de género e empoderar todas as mulheres e raparigas. Na África Subsaariana, Oceania e Ásia Ocidental, meninas ainda enfrentam barreiras para entrar tanto na escola. As mulheres na África do Norte ocupam menos de um a cada cinco empregos pagos em setores que não sejam a agricultura. Portugal tem sido motor para o desenvolvimento de medidas e ações, promovendo o Plano de Ação para a Promoção da Igualdade e Equidade de Género/CPLP. (ONU, 2017, p. 20).

ODS 6: garantir a disponibilidade e a gestão sustentável da água potável e do saneamento para todos. Em 2015, 91\% da população global usou uma fonte de água potável aprimorada, comparado a $76 \%$ em 1990. Contudo, 2,5 bilhões de pessoas não têm acesso a serviços de saneamento básico, como casas de banho ou latrinas. Portugal, apoiado por recursos financeiros próprios ou mobilizados ao nível internacional, tem envolvido o setor público e o privado e a sociedade civil, nesta matéria. (ONU, 2017, p. 21).

ODS 7: garantir o acesso a fontes de energia fiáveis, sustentáveis e limpas para todos. Atualmente, mais de um bilhão de pessoas ainda não têm acesso à eletricidade moderna e três bilhões de pessoas dependem de madeira, carvão, carvão vegetal ou dejetos animais para cozinhar e obter aquecimento.

Destacam-se as

[...] políticas públicas do setor energético com Cabo Verde, o Protocolo de Cooperação, que inclui capacitação técnica institucional, nas áreas de combustíveis e energia elétrica; com Moçambique, que abrange os setores da energia convencional, energia renovável e eficiência energética, e respetivo Plano de Ação; e com Timor-Leste, o Memorando de Entendimento nas áreas da energia, geologia e minas. Realça-se, igualmente, o apoio prestado a atores da sociedade civil, em particular ONGD, no desenvolvimento de tecnologias e boas práticas, nomeadamente na Guiné-Bissau e São Tomé e Príncipe, procurando apoiar as populações a tirar partido destas novas tecnologias. (ONU, 2017, p. 22).

ODS 8: promover o crescimento económico inclusivo e sustentável, o emprego pleno e produtivo e o trabalho digno para todos. Aproximadamente 2,2 bilhões de pessoas vivem abaixo da linha da pobreza e a erradicação do problema, só é possível por meio de empregos bem pagos e estáveis; 470 milhões de empregos são necessários mundialmente para a entrada de novas pessoas no mercado de trabalho até 2030. Portugal é signatário de diversos Memorandos de Cooperação nas áreas do emprego e formação profissional, ação inspetiva, e proteção e segurança social; tem acordos de cooperação com Cabo Verde e São Tomé e Príncipe. (ONU, 2017, p. 23-24).

ODS 9: construir infraestruturas resilientes, promover a industrialização inclusiva e sustentável e fomentar a inovação. Para muitos países africanos, principalmente os de baixo rendimento, os limites na infraestrutura afetam 
em cerca de $40 \%$ na produtividade das empresas. Portugal tem promovido o apoio ao desenvolvimento de infraestruturas sustentáveis e resilientes, em Moçambique, Cabo Verde e Angola. (ONU, 2017, p. 25).

ODS 10: reduzir as desigualdades no interior dos países e entre países. A cooperação portuguesa visa o respeito pelos Direitos Humanos, pela democracia e pelo Estado de direito. Portugal procura apoiar os Países Africanos de Língua Oficial Portuguesa e Timor-Leste, através da promoção da proteção social, inclusão social e emprego. (ONU, 2017, p. 26).

ODS 11: tornar as cidades e comunidades inclusivas, resilientes e sustentáveis. Metade da humanidade vive nas cidades atualmente. Em 2030, quase $60 \%$ da população mundial viverá em áreas urbanas. É de referir a Campanha Cidades Resilientes das Nações Unidas, que promove a implementação de medidas de redução de catástrofes por parte das autoridades locais como um dos seus princípios orientadores. (ONU, 2017, p. 28).

ODS 12: garantir padrões de consumo e de produção sustentáveis, com as seguintes orientações:

[...] desenvolver a economia circular, com enfoque na desmaterialização, economia colaborativa e consumo sustentável, conceção de produtos, uso eficiente e valorização de recursos; alterar os modelos de produção e consumo: menos recursos, mais eficiência e menos impactos ambientais; aumentar as taxas de recolha, reciclagem e valorização globais e setoriais para os diferentes materiais constituintes dos resíduos; promover práticas de compras públicas ecológicas e sustentáveis; garantir o acesso à informação, participação do público na tomada de decisão e acesso à Justiça em matéria de Ambiente; promover comportamentos mais sustentáveis do ponto de vista ambiental, através da fiscalidade verde. (ONU, 2017, p. 29).

ODS 13: adotar medidas urgentes para combater as alterações climáticas e os seus impactos. Salienta-se o plano para alavancar financiamento público e privado para o clima, visando mobilizar 100 mil milhões de dólares por ano até 2020, trabalho ao qual Portugal se associou e se comprometeu a prosseguir o desenvolvimento de parcerias com os PALOP. (ONU, 2017, p. 32).

ODS 14: conservar e usar de forma sustentável os oceanos, mares e os recursos marinhos para o desenvolvimento sustentável. As orientações são:

[...] prevenir e reduzir a poluição e lixo marinhos; limitar o impacto da pesca no meio marinho e adaptar a pesca à proteção das espécies; promover a proteção, restauração e gestão sustentável dos ecossistemas marinhos e costeiros e da biodiversidade marinha; fomentar o desenvolvimento local das comunidades costeiras; potenciar as áreas de investigação e fiscalização de natureza tributária, fiscal e aduaneira; aprofundar a política de vigilância marítima; aumentar o conhecimento científico, desenvolver capacidades de investigação e transferir tecnologia marinha. (ONU, 2017, p. 52). 
ODS 15: proteger, restaurar e promover o uso sustentável dos ecossistemas terrestres, gerir de forma sustentável as florestas, combater a desertificação, travar e reverter a degradação dos solos e travar a perda de biodiversidade. No plano internacional, note-se a participação ativa de Portugal na

[...] Convenção de Berna sobre a Vida Selvagem e os Habitats Naturais na Europa, na Convenção de Bona sobre Espécies Migradoras da Fauna Selvagem, na Convenção de Ramsar sobre as Zonas Húmidas com interesse internacional para as aves aquáticas e na Convenção de Washington sobre o Comércio Internacional de Espécies da Fauna e da Flora Selvagem Ameaçadas de Extinção. (ONU, 2017, p. 72).

ODS 16: promover sociedades pacíficas e inclusivas para o desenvolvimento sustentável, proporcionar o acesso à justiça para todos e construir instituições eficazes, responsáveis e inclusivas a todos os níveis. No âmbito da CPLP e da cooperação com os PALOP, destacam-se:

[...] o apoio à harmonização técnica da legislação em matéria aduaneira dos países da CPLP, no quadro da Organização Mundial das Alfândegas; os Programas de Cooperação Técnico-Policial nas áreas de segurança, fronteiras e proteção civil; e os projetos de Cooperação Técnico-Militar, contribuindo para que as instituições militares dos países parceiros sejam de forma crescente e sustentada, produtores de segurança e indutores de desenvolvimento, através das assessorias técnicas, formação e instrução, recuperação de infraestruturas, fornecimento de equipamento, a par de atividades que contribuam para reforço da segurança e autoridade do Estado. (ONU, 2017, p. 76-80).

ODS 17: reforçar os meios de implementação e revitalizar a parceria global para o desenvolvimento sustentável e no sentido de reforçar a qualidade da sua ação externa no âmbito da cooperação internacional e para o desenvolvimento sustentável. Portugal,

[...] investe na capacitação institucional e humana; transição para uma lógica de cofinanciamento nacional, europeu e internacional, público e privado, através do recurso a novas e diversas fontes de financiamento e envolvimento dos agentes económicos, do mundo académico e da sociedade civil. (ONU, 2017, p. 81-85).

Deste modo, a abordagem integrada, centrada nas pessoas e sensível ao planeta inerente à Economia Social e Solidária está em harmonia com os desafios de desenvolvimento identificados no processo dos ODS, pois, o potencial em relação a estas áreas são fundamentais para o desafio do desenvolvimento socialmente sustentável. (ONU, 2014, p. 9).

\section{ODS em ação pelo mundo}


Com as mudanças verificadas no mundo, os esforços realizados pelos Objetivos de Desenvolvimento do Milénio, apesar de terem representado um esforço em torno de objetivos comuns, demonstraram necessidade de avançar para a inclusão mais acentuada, no âmbito dos Direitos Humanos. "As alterações climáticas e a crise económica e financeira, demonstram que os componentes do desenvolvimento social, económico e ambiental estão interligados". (INSTITUTO CAMÕES DA COOPERAÇÃO E DA LÍNGUA, 2014, p. 3).

Tomando como ponto de partida a ONG portuguesa AMI - Assistência Médica Internacional, e o seu projeto, "ODS em Ação", pretende-se contribuir para uma sociedade mais informada e ativa na promoção do desenvolvimento sustentável e no respeito pelos Direitos Humanos. Para tal, consideramos os seguintes países, Portugal, Brasil, São Tomé e Príncipe e Síria, no sentido de representar exemplos concretos de desenvolvimento de projetos pelo mundo, nos quais as atividades e missões são desenvolvidas com o objetivo de cumprir cada um dos ODS.

O Brasil teve participação no planeamento dos ODS, participou nas negociações e concordou com os ODS. Entre os objetivos assumidos estão: acabar com a pobreza e com a fome, promover o bem-estar da população, assegurar educação, igualdade de género e empoderamento às mulheres, fazer uma gestão responsável da água, promover o crescimento económico sustentável e combater as mudanças climáticas. Como país-membro da ONU, - Brasil terá diversos desafios para adotar essa agenda de longo prazo e internalizar os compromissos com ações concretas que ajudem a transformar a realidade do país e do mundo.

No ano de 2016, o projeto: "Apoio ao Desenvolvimento Agro-Comunitário", no âmbito da alimentação e nutrição, pretende dar continuidade ao ODS 2 - Erradicar a fome, alcançar a segurança alimentar, melhorar a nutrição e promover a agricultura sustentável.

Este projeto foi dinamizado pela AMI, em parceria com a ONG local, a ACOM (Associação Comunitária das Mulheres) e teve como beneficiários 152 pessoas. Tem como objetivo proporcionar, através da perfuração de um poço profundo, da construção de uma pocilga e da implantação de um pomar de hortifruticultura, melhores condições de produção e geração de rendimentos, fortalecendo o associativismo e melhorando a qualidade de vida, saúde e nutrição dos associados e comunidade. (AMI, 2016).

No ano de 2017, o projeto: "Saúde, Educação e Arte: Um encontro com a cidadania", em parceria com uma ONG local, cujos beneficiários são 1.200 pessoas. Pretende garantir o acesso à saúde em serviços especializados específicos na vila de Milagres e promover a adoção de práticas saudáveis pela população do município. Trabalha com grupos de mulheres ativistas na pro- 
moção da saúde e adoção de práticas saudáveis, passando a mensagem nas ações de sensibilização e colocar em prática os ODS. (AMI, 2016).

O Projeto: "Formação, Produção e Comercialização nos empreendimentos de Economia Solidária: uma abordagem agroecológica de Género e Técnico-Operativa", leva ao fortalecimento de quatro associações de economia solidária que concebem produtos artesanais e tem o objetivo de promover a sustentabilidade das organizações, através da capacitação dos seus membros e o fornecimento de ferramentas de apoio à produção e também, fomentar a dinamização comunitária e a igualdade de género. (AMI, 2016).

Na Síria, o Projeto: "Criação de uma rede comunitária de saúde mental e apoio psicossocial a norte de Aleppo", tem como objetivos: quebrar barreiras e assumir a liderança no estabelecimento de uma rede de Saúde Mental e Apoio Psicossocial, onde os estigmas são desconstruídos, a população torna-se informada e exerce o seu direito a aceder a serviços de acordo com as suas necessidades. No norte da Síria, a população deslocada interna que foge do conflito armado, bem como a população que os acolhe, encontra-se perante um enorme desafio de vida, onde a violenta guerra civil, que assola o país, se tornou num preocupante quotidiano. A Chefe de Direitos Humanos, Michelle Bachelet, considera que os números são assustadores, vergonhosos e profundamente trágicos, defendendo que envolvidos no conflito e Estados influentes "muito poderosos" deixem de lado as suas diferenças políticas. A alta comissária dos Direitos Humanos revelou que registou mais de 1.000 mortes de civis no norte da Síria nos últimos quatro meses. (NAÇÕES UNIDAS, 2019).

Perante a continuidade do conflito, sem resolução à vista, a necessidade de cuidados de Saúde Mental e Apoio Psicossocial torna-se uma realidade cada vez mais urgente. Para tal, nesta região, os serviços estão disponíveis e dotados de equipamentos e pessoal técnico qualificado. O projeto irá exercer uma forte componente de informação e sensibilização à população abrangendo 4.000 pessoas. (AMI, 2016).

Em São Tomé e Príncipe, o Projeto: "Porto de Partida", tem como objetivos: a redução da pobreza através da melhoria das condições higiénico-sanitárias, a promoção da literacia em saúde e o saneamento do meio e intervenções de desenvolvimento local.

Caué é o distrito mais pobre de São Tomé, com frágil tecido económico, baixos rendimentos e iliteracia, conducentes a uma economia de subsistência e à criação animal arbitrária e desenvolvida informalmente. O projeto da AMI visa sensibilizar a população para os malefícios da atual situação de criação animal; construção de infraestruturas para acolher animais e proceder ao seu abate em condições de higiene adequadas; desenvolver atividades de cariz social que permitam combater situações de pobreza extrema. (AMl, 2016). 


\section{Os desafios da cidadania no mundo}

É fundamental considerar que, a cidadania ativa e paritária, tem por base uma cultura de responsabilidade social, valorizando a participação cívica, potenciar a inclusão e a coesão social, eliminar as assimetrias económicas, sociais, culturais e territoriais, contribuindo deste modo, para a inversão de trajetórias de exclusão social.

De acordo com a opinião do Secretário Geral da ONU, "os direitos consagrados na Declaração Universal dos Direitos Humanos pertencem a todos, em qualquer lugar, logo todas as medidas para defender os direitos humanos promovem o alívio das tensões, bem como proporcionam desenvolvimento sustentável e sustentar a paz". (NAÇÕES UNIDAS, 2019, p.12).

A cidadania acompanha as mudanças estruturais que afetam mulheres e homens. Estas mudanças estruturais dizem respeito a dois aspetos da vida quotidiana que condicionam a cidadania: os valores laborais tradicionais entraram num processo de radical mudança; e simultaneamente, os tempos das nossas vidas foram consideravelmente alterados, em parte como resultado da alteração dos valores laborais. (OCDE, 1994, p. 34).

Balmer-Cao (2018, p.35) salienta três traços desta mudança:

[...] primeiro, o declínio dos valores transcendentes e/ou abstratos, a disciplina, a assiduidade, a perseverança, têm menos influência do que os valores concretos, como a boa vida. De um modo geral, os valores com recompensa imediata tendem a prevalecer sobre os valores com recompensa adiada ou difícil de alcançar. O segundo traço prende-se com o declínio da racionalidade económica no trabalho. O terceiro traço consiste no facto de que a concretização dos valores sofreu duas mudanças: a coletivização dos sucessos ou fracassos, não é o individuo, mas a sociedade que é responsável do seu sucesso ou fracasso.

A educação tem assim a difícil tarefa de atuar em diversos papéis dentro da sociedade em "plena metamorfose". É através da educação baseada nos princípios de igualdade de oportunidades, que mediante a diversificação dos serviços educacionais de modo a entender as diferenças individuais, que todos nós devemos promover a prática da cidadania, respeitando a diversidade.

Este é um primeiro passo para que a educação se coloque na linha de globalização, reforçando a defesa dos Direitos Humanos como um dos seus elementos essenciais, dentro de uma democracia comunicativa e "cosmopolítica", que, enfatiza o desenvolvimento pluralista e interdependente da sociedade global, o respeito pela nova arquitetura civilizacional assente na diversidade das culturas e de objetivos, a responsabilidade social global, a "participação democrática multifacetada", a "política emancipatória" ligada à 
"política da vida ou de auto-realização". (GIDDENS, 1995, p.129).

Neste processo assume particular importância valores como a tolerância, a democracia, o respeito pela diversidade e a luta contra as desigualdades, numa dimensão de educação para a cidadania, no quadro do pleno respeito pelos Direitos Humanos e com a concretização dos ODS. Assim, a economia solidária surge como uma estratégia para um novo modelo de desenvolvimento sustentável, solidário, visto que todos os envolvidos beneficiam dos seus resultados económicos, sociais, políticos e culturais. Torna-se, pois necessário passar para uma imagem viva e dinâmica, aberta ao contacto e à solidariedade com outras comunidades, ou seja, urge "formular formas de pensamento e ação que sejam ambiciosos, que sejam capazes de pensar e atuar nas escalas nacionais e globais". (SANTOS, 2004).

A Economia Solidária tornou-se num importante instrumento de combate à exclusão social e à pobreza, pois permite a incrementação do emprego e rendimento para muitos e variados trabalhadores, propondo a construção de relações económicas mais justas, solidárias e sustentáveis, fomentando desta forma o desenvolvimento local justo e solidário. (GOMES, 2007).

Torna-se necessário fortalecer a Economia Solidária como estratégia de inclusão económica e social, sendo que esta oferece um caminho com potencial para o desenvolvimento local sustentável e solidário. (JESUS, 2003).

O desenvolvimento sustentável fortalece institucionalmente os estados e municípios; favorece o surgimento de serviços públicos eficientes; garante a qualidade e o controle social destes serviços através da participação popular; torna possível a sua execução como forma de gerar trabalho e distribuir renda, na perspetiva da Economia Solidária. (MANCE, 2004, p. 276). Ao planear-se o desenvolvimento sustentável, cabe considerar a Economia Solidária como eixo estratégico, pois sem isso as propostas resultantes não serão, social e economicamente, sustentáveis. (RBSES, 2000).

As redes de economia solidária relacionam-se diretamente com a promoção do desenvolvimento sustentável à medida que as suas atividades visam o respeito ao meio ambiente, respeito ao ser humano e a busca por novos modos de produção que sejam economicamente viáveis a todos os participantes. (SINGER, 2004, p. 20).

A propagação do conceito de desenvolvimento sustentável trouxe para as organizações a reflexão sobre os impactos sociais e ambientais oriundos da sua atividade, retornando para uma visão mais individual e microeconómico; o novo paradigma para o desenvolvimento sustentável requer construir consensos e superar impasses ambientais. (HALL, 2010).

A economia solidária parte de uma perspetiva que propõe a inovação e criação de novas formas de mercado, a socialização da produção de 
conhecimento e igualdade de direitos. De acordo com esta ótica, a rede de economia solidária e o desenvolvimento sustentável visam a melhoria da sociedade, mas apresentam conceções difíceis de serem materializadas dado os seus ideais sociais, económicos e ambientais. (SINGER, 2008).

$\mathrm{Na}$ esfera internacional, a sustentabilidade política visa integrar o sistema de preservação de conflitos e guerras com empenho na promoção contínua da paz. (CARVALHO, 2011).

A relação entre os direitos humanos, a sustentabilidade e o desenvolvimento evidencia a necessidade de se promover o pleno gozo de todos os direitos humanos e fundamentais. Somente assim poder-se-á atingir o mínimo desejável de justiça social, qualidade de vida, equilíbrio ambiental e desenvolvimento sustentável na esfera global. (CARVALHO, 2013).

Nos últimos duzentos anos,"[...] os direitos dos seres humanos uniram-se às constituições e práticas políticas legais de muitos países; foram concetualizados como direitos dos cidadãos, garantidos diretamente pelo Estado e aplicado coercivamente pelos tribunais: civil, social, político, económico e cultural" (SANTOS, 2014, p. 23).

Direitos Humanos são produtos sócio-históricos forjados das diferentes lutas populares empreendidas em favor das condições de vida decentes. Surgem da tomada de consciência em todos os momentos históricos dos valores sociais, fundamentos e condições que os negam, além da necessidade de se organizar para lutar pela sua concretização. Esta visão dos Direitos Humanos como um projeto a ser concluído na prática política e cultural dos povos, afirma o caráter fundamental que as lutas sociais têm, bem como a influência das condições históricas em que eles surgem e se desenvolvem. (FUNDACIÓN, 2010).

A dignidade humana destaca e caracteriza a pessoa de outros seres vivos, por sua razão, vontade, liberdade, igualdade e historicidade. Os artigos $1 .^{\circ}, 22 .^{\circ}$ e $23.0^{\circ}$ da Declaração Universal dos Direitos Humanos, referem-se expressamente dignidade humana: "Todos os seres humanos nascem livres e iguais em dignidade e direitos e dotados de razão e consciência devem comportar-se fraternalmente". (Artigo 1.०).

Apesar de não existir uma só definição de Direitos Humanos, a maioria reflete e enfatiza ao considerarem que a pessoa possui por sua própria natureza e dignidade, sendo aqueles inerentes e não uma concessão da comunidade política; quais são os que especificam em cada momento histórico as demandas da dignidade humana, liberdade e igualdade, devem ser reconhecidas positivamente pela ordem jurídica nacional e internacional; que são aqueles que correspondem à pessoa por essência, simultaneamente no seu aspeto corporal, espiritual e social, e que deve ser reconhecido e respeitado por todo o poder ou autoridade e por todas as normas legais positivas, mas que eles cedem no seu 
exercício diante das demandas do bem comum. (TRUYOL y SERRA, 1984).

$\mathrm{O}$ número de pessoas que vivem livres da miséria, sem medo e que não sejam alvo de discriminação tem vindo a crescer. No entanto, "existem situações de recuo como conflitos domésticos, questões religiosas ligadas ao fanatismo ou meramente por diferenças culturais" que impedem a concretização plena da visão da Declaração Universal de um mundo em que todas as pessoas são livres e iguais. (AMNISTIA INTERNACIONAL, 2018).

Por último, ao refletirmos sobre o significado da educação para os Direitos Humanos, procuramos também aprender as suas relações com uma cultura de paz. Justiça, Liberdade, Solidariedade, Igualdade, Tolerância, Paz, entre outros, são valores que dão sentido à vida e dão base para o que compreendemos por direitos humanos. Educar para a solidariedade supõe que, pela vivência e na transversalidade, possibilite a reflexão, a sensibilização e a consciencialização sobre a importância do respeito ao ser humano. (ASSMANN, 2000).

\section{Referências}

AMI. Projetos dos Objetivos de Desenvolvimento Sustentável. Disponível em: https://ami.org.pt/missao/formacao-producao-comercializacao-nosempreedimentos-economia-solidaria-abordagem-agroecologica-generotecnico-operativa/https://ami.org.pt/missao/construcao-da-escola-de-gabacar/. Acesso em: 14 jul. 2019.

AMI. Missões em São Tomé e Príncipe. Disponível em: https://ami.org.pt/ missao/porto-de-partida-sao-tome-principe/. Acesso em: 15 jul. 2019.

AMI. Missões na Síria. Disponível em: https://ami.org.pt/missao/criacao-redecomunitaria-saude-mental-apoio-psicossocial-no-norte-aleppo-siria/. Acesso em: 15 jul. 2019.

AMI. Missões de Cidadania. Disponível em: https://ami.org.pt/missao/saudeeducacao-arte-um-encontro-cidadania-brasil/. Acesso em: 16 jul. 2019.

AMI. Missões ODS em Ação. Disponível em: https://ami.org.pt/missao/ capacitacao-de-50-criancas-noivas/. Acesso em: 16 jul. 2019.

AMNISTIA INTERNACIONAL. Os direitos humanos e a pobreza. 2018. Disponível em: https://www.amnistia.pt/os-desc-sao-direitos-humanos/. Acesso em: 17 jul. 2019. 
ANNAN, Kofi. Relatório do Milênio. ONU, 2001. Disponível em: https://unric. org/pt/kofi-annan-gana/. Acesso em: 23 jul. 2019.

ASSMANN, Hugo; SUNG, Jung Mo. Competência e sensibilidade solidária: educar para a esperança. Petrópolis, RJ: Vozes, 2000.

BALMER-CAO. Les nouvelles frontiéres du genre. Paris, L'Harmattan - Logiques Sociales, 2018.

BAUMAN, Zygmunt. Comunidade. A busca por segurança no mundo atual. Rio de Janeiro: Jorge Zahar Editor, 2003.

BENEVIDES, Maria Victoria. Educação em Direitos Humanos: de que se trata? Palestra de abertura do Seminário de Educação em Direitos Humanos, São Paulo, 2016. Disponível em: https://www.hottopos.com/convenit6/victoria. htm. Acesso em: 22 jul.2019.

CARVALHO, Edson Ferreira de. Meio ambiente e direitos humanos. 2. ed. Curitiba: Juruá, 2011.

CARVALHO, Sonia Aparecida de. O direito ao desenvolvimento sustentável como direito humano fundamental. In: GORCZEVSKI, Clovis (org.). Direitos humanos e participação política. V. IV. Porto Alegre: Imprensa Livre, 2013.

\section{CONFERÊNCIA MUNDIAL SOBRE DIREITOS HUMANOS - Declaração e}

Programa de Ação de Viena. Disponível em: http://www.gddc.pt/direitoshumanos/textos-internacionais-dh/tidhuniversais/decl-prog-accao-viena. html. Acesso em: 19 jul. 2019.

CONSELHO EMPRESARIAL PARA O DESENVOLVIMENTO SUSTENTÁVEL. Uma visão inspiradora para uma economia sustentável na Europa: assumir as metas de desenvolvimento sustentável, 2017. Disponível em: https://bcsdportugal. org/publicacao-europeia/. Acesso em: 27.jul. 2019.

FUNDACIÓN Juan Vives Suriá. Derechos humanos: historia y conceptos básicos, Fundación Editorial El perro y la rana Fundación Juan Vives Suriá Defensoría del Pueblo, 2010.

GIDDENS, Anthony. As consequências da modernidade. Lisboa: Celta, 1995. 
GOMES, Fabiana Pereira et al. Economia solidária e desenvolvimento local e sustentável. Projeto Casa Brasil: MTE, SENAES, 2007.

GUERRA MARTINS, A.M. Direito Internacional dos Direitos Humanos. Coimbra: Almedina, 2006.

HALL, J. K.; DANEKE, G. A.; LENOX, M. J. Sustainable development and entrepreneurship: past contributions and future directions. Journal of Business Venturing, Indiana, 25 (5), p. 43, 2010.

IGNATIEFF, Michael. Los derechos humanos como política e idolatría. Barcelona: Paidós, 2001.

INSTITUTO CAMÕES DA COOPERAÇÃO E DA LÍNGUA. Documento de Posição de Portugal sobre a Agenda 2015, Lisboa, 2014. Disponível em: https://www. instituto-camoes.pt/images/agendaPos2015/DocPosicao_POS2015.pdf. Acesso em: 31 jul. 2019.

JESUS, Pablo. Desenvolvimento Local. In: CATTANI, Antonio David(org.). A outra economia. São Paulo: Veraz Editores, 2003.

MANCE, Euclides André. Fome zero e economia solidária - O desenvolvimento sustentável e a transformação estrutural do Brasil. Curitiba: IFiL, Editora Gráfica Popular, 2004.

MAGENDZO, Abraham. Educación en Derechos Humanos: un desafío para los docentes de hoy. Santiago: LOM Ediciones, 2006.

MONTEIRO, Reis. Sobre o direito à educação. Coimbra, IGC, 2013.

MOREIRA, Vital; GOMES, Marcelino. Compreender os direitos humanos: manual de educação para os direitos humanos, Coimbra, Coimbra Editores, 2013.

NAÇÕES UNIDAS. Carta das Nações Unidas, 1945. Disponível em: https://unric.org/pt/wp-content/uploads/sites/9/2009/10/Carta-dasNa\%C3\%A7\%C3\%B5es-Unidas.pdf. Acesso em: 17 jun. 2019.

OCDE. The OECD Jobs Study, 1994. Disponível em: https://www.oecd.org/els/ emp/1941679.pdf. Acesso em: 26 jun. 2019. 
ONU. Economia Social e Solidária e o Desafio do Desenvolvimento Sustentável, julho, 2014. Disponível em: https://www.unrisd.org/unrisd/website/document.nsf/ (httpPublications)/20820DB0F169D8D5C1257D1D0041AA97?OpenDocument. Acesso em: 11 mai. 2019.

ONU. Relatório nacional sobre a implementação da Agenda 2030 para o Desenvolvimento Sustentável, julho, Nova lorque, 2017. Disponível em: https:// sustainabledevelopment.un.org/content/documents/15771 Portugal2017. pdf. Acesso em: 21 mai. 2019.

RAWLS, John. El derecho de gentes. In: SHUTE, Stephen; HURTLEY, Susan (eds.). De los derechos humanos. Madrid: Trotta, 1998. p. 47-85.

RBSES. Construindo a Rede Brasileira de SocioEconomia Solidária - Documento de Trabalho do Encontro Brasileiro de Cultura e SocioEconomia Solidárias. Mendes-RJ, 11-18/6/2000. Série: Semeando Socioeconomia № 4. PACS, Rio de Janeiro, 2000. Disponível em: http://www.mobilizadores.org.br/wpcontent/uploads/2014/05/rede-brasileira-de-socioeconomia-solidria.pdf. Acesso em: 8 ago. 2019.

SANTOS, Boaventura de Sousa; Rodríguez, César. Introdução: para ampliar o cânone da produção. In: Boaventura de S. S. (org.). Produzir para viver: os caminhos da produção não capitalista. Porto: Afrontamento, 2004.

SANTOS, Boaventura de Sousa. Democracia al borde del caos. Ensayo contra la autoflagelación. Bogotá: Siglo del Hombre Editores, 2014.

SINGER, Paul. Desenvolvimento capitalista e desenvolvimento solidário. Estudos avançados, São Paulo, v. 18, n. 51, p.12- 25, 2004.

TAVARES, Celma. Barbarie en la democracia. Salamanca: Ediciones Universidad de Salamanca, 2006.

TRUYOL y SERRA, Antonio. Los derechos humanos. Madrid: Tecnos, 1984.

UNESCO. Educação para os Objetivos de Desenvolvimento Sustentável Objetivos de Aprendizagem, Educação 2030, Unesco, 2017. Disponível em: https://unesdoc.unesco.org/. Acesso em: 23 mai. 2019.

UNESCO. Desenvolvimento Sustentável. Disponível em: https://www. 
unescoportugal.mne.pt/pt/temas/um-planeta-um-oceano/educacao-para-odesenvolvimento-sustentavel. Acesso em: 3 jul. 2019.

UNRIC. Objetivos de Desenvolvimento Sustentável. Disponível em: https:// www.unric.org/pt/actualidade/27555-declaracao-e-plataforma-de-accao-debeijing-quinze-anos-apos-a-sua-adopcao. Acesso em: 3 jul. 2019.

Recebido em: 22 de abril de 2020. Aprovado em: 21 de abril de 2021. 